\title{
Additive manufactured metallic implants for orthopaedic applications
}

\author{
Kwok-Chuen Wong $^{1^{*}}$ and Peter Scheinemann ${ }^{2}$
}

\begin{abstract}
Metallic implants are commonly used in various orthopaedic surgeries, like fracture fixation, spinal instrumentation, joint replacement and bone tumour surgery. Patients may need to adapt to the fixed dimensions of the standard implants. It may result in suboptimal fit to the host bones and possible adverse clinical results. The standard traditional implants may not address the reconstructive challenges such as severe bone deformity or bone loss after implant loosening and bone tumour resection. With the advent of digital technologies in medical imaging, computer programming in three-dimensional (3D) modelling and computer-assisted tools in precise placement of implants, patient-specific implants (PSI) have gained more attention in complex orthopaedic reconstruction. Additive manufacturing technology, in contrast to the conventional subtractive manufacturing, is a flexible process that can fabricate anatomically conforming implants that match the patients' anatomy and surgical requirements. Complex internal structures with porous scaffold can also be built to enhance osseointegration for better implant longevity. Although basic studies have suggested that additive manufactured (AM) metal structures are good engineered biomaterials for bone replacement, not much peer-reviewed literature is available on the clinical results of the new types of implants. The article gives an overview of the metallic materials commonly used for fabricating orthopaedic implants, describes the metal-based additive manufacturing technology and the processing chain in metallic implants; discusses the features of AM implants; reports the current status in orthopaedic surgical applications and comments on the challenges of AM implants in orthopaedic practice.
\end{abstract}

Keywords: 3D printing, additive manufacturing, electron beam melting, orthopaedic implants, patient-specific, porous scaffold

\section{INTRODUCTION}

Metallic implants are commonly used in various orthopaedic surgeries, like fracture fixation, spinal instrumentation, joint replacement and bone tumour surgery. In contrast to custom-made orthopaedic implants, standard off-the-shelf implants have the advantages of being less expensive, less time-consuming in mass production, higher surgical flexibility with different sizes and length. Traditionally, patients may need to adapt to the fixed dimensions of standard implants. It may result in suboptimal fit to the host bones and possible adverse clinical results. The standard traditional implants may not address the reconstructive challenges such as severe bone deformity or bone loss after implant loosening and bone tumour resection. With the advent of digital technologies in medical imaging, computer programming in three-dimensional (3D) modelling [1] and computer-assisted tools [2-5] in precise implant placement, there has been increasing interest in using patientspecific implants for complex orthopaedic reconstruction [6-16].

Over the past several years, additive manufacturing has gained popularity in medical sectors, and new applications are evolving rapidly in various orthopaedic procedures [17]. Traditionally, metallic orthopaedic implants are produced by subtractive machining, in which material is successively removed from a solid metal block until the desired shape is reached. The other traditional manufacturing method is by formative shaping. Mechanical forces are applied to the rough material to form it into the desired shape, like casting or forging. Currently, most commercial activity in orthopaedics has been for the standard-sized implants manufactured by traditional manufacturing methods. Additive manufacturing tech-

\footnotetext{
${ }^{1}$ Department of Orthopaedics and Traumatology, Prince of Wales Hospital, The Chinese University of Hong Kong, Hong Kong 852, China

${ }^{2}$ Implantcast GmbH, D-21614 Buxtehude, Germany

*Corresponding author (email: skcwong@ort.cuhk.edu.hk)
} 
nology is, however, a flexible process that does not require multiple steps for production or any additional tooling with inventory. It reduces the cost required to manufacture a small batch of complex implants. The implant can then be customised to a patient's anatomy (patient-specific) and surgical requirements (diseasespecific) using a patient's medical imaging like computer tomography (CT) or magnetic resonance imaging (MRI) scans. Anatomically matched, patient-specific implants have the potential advantages of reducing surgical time and providing superior comfort with a faster recovery. The additive manufactured (AM) implants with engineered internal porous structures not only promote osseointegration but also reduce the mismatch in stiffness between natural bone and implant. It may minimise stress shielding related bone resorption and improve the longevity of orthopaedic implants. Although porous materials were clinically useful before the era of additive manufacturing, the new technology allows integration of porous structures with other geometric complexities, such as fine surface features, internal porous interconnectivity, and nonporous structures into one manufacturing process. The comparison between traditional and AM orthopaedic implants is shown in Table 1.

Although in vitro and in vivo studies have suggested that AM metal structures are good engineered biomaterials for bone replacement, not much peer-reviewed literature is available on the results of the new type of implants. Lack of demonstrated superior performance and regulatory standards of the AM implants are some concerns that may hinder their use in orthopaedic practice. The article gives an overview of the metallic materials commonly used for fabricating orthopaedic implants, describes the metal-based additive manufacturing technology and the processing chain in metallic implants; discusses the features of AM implants; reports the current status in orthopaedic surgical applications and comments on the challenges of AM implants in orthopaedic practice.

\section{ADDITIVE MANUFACTURING OF ORTHOPAEDIC METALLIC IMPLANTS}

Additive manufacturing is a group of processes by which 3D objects are constructed from a digital model by successively depositing material such as plastic or metal in layers. A patient- and the defect-specific orthopaedic implant can be designed and then manufactured, using the patient's own CT/ MR medical imaging data. As the technology is additive in contrast to the traditional subtractive machining process, it has fewer design con- straints that account for its versatility in manufacturing 3D objects with accurate complex geometries. Therefore, implants can be designed with geometry to fit the surgical requirement for the patient, rather than to fit in with the manufacturing constraints of the production process. Also, changes in the design require no additional equipment or tools. It allows fabrications of different implants with highly complex parts in the same batch of the manufacturing process. The lower customisation cost may facilitate the manufacturing of patient-specific orthopaedic implants [18]. Also what usually take weeks to manufacture using traditional methods can now be done in several hours. The lead manufacturing time of custom parts may be reduced, and it facilitates patient-specific orthopaedic applications.

\section{Metallic materials in orthopaedic implants}

There are many types of metallic materials that can be used for fabricating orthopaedic implants. In the International Standards for Organization standards (ISO5832) under the general title "Implant for surgery - metallic materials", twelve types of metallic materials can be categorised into titanium-based, cobalt-based and steelbased alloys [19]. The most common materials, titanium6aluminium-4vanadium (Ti-6Al-4V) and cobalt-chromium-molybdenum (CoCrMo) alloys are available in powder forms for additive manufacturing in orthopaedic implants.

Titanium Ti-6Al-4V wrought alloy (ISO5832-2) is the widely used titanium-based alloy. It has become one of the principal biomedical materials for fabricating orthopaedic implants because of its unique properties, including superior corrosion resistance, reduced elastic modulus and high mechanical strength to weight ratio when compared to stainless steel and CoCrMo alloys $[20,21]$. The biocompatibility of Ti-6Al-4V is excellent especially when direct contact with tissue or bone is required. Ti alloy has been observed to provide a favourable surface for osteoblast adhesion and osteogenic differentiation. It can form a superficial oxide layer that promoted osteoblast attachment through binding of adsorbed fibronectin to surface-expressed integrins [22]. Another study has shown that the culture of osteoblastlike cells on Ti-6Al-4V alloy substrate could promote osteoblastic maturation by creating an osteogenic environment that contains bone morphogenetic proteins and could enhance bone formation [23]. The results suggested that modifying surface structure of the titanium implants can promote osseointegration at the bone-implant interface for better implant fixation. Therefore, the 
Table 1 Comparison between traditional and additive manufactured orthopaedic implants

\begin{tabular}{|c|c|c|}
\hline & Traditionally manufactured implants & Additive manufactured implants \\
\hline Metal materials & - Medical grade titanium and cobalt chrome-based alloys & - Same as traditional implants \\
\hline $\begin{array}{l}\text { Manufacturing } \\
\text { methods }\end{array}$ & $\begin{array}{l}\text { Subtractive machining: Material is successively removed from a } \\
\text { solid block until the desired shape is reached, like turning, } \\
\text { milling, drilling. } \\
\text { - Formative shaping: Mechanical forces are applied to the material } \\
\text { to form it into the desired shape, like bending, casting, forging, } \\
\text { pressing. } \\
\text { - Need specific tool's design, development and production } \\
\text { - Suitable for mass production } \\
\text { - More mature technology than additive manufactured implants }\end{array}$ & $\begin{array}{l}\text { Additive manufacturing is a process of joining metal } \\
\text { materials layer upon layer to make objects from } 3 \mathrm{D} \\
\text { model data until the final implant is built. } \\
\text { - Flexible supply chains as no specific tools needed for this } \\
\text { process. } \\
\text { - Ideal for both prototyping and low volume patch (as low } \\
\text { as one if required) }\end{array}$ \\
\hline $\begin{array}{l}\text { Mechanical } \\
\text { properties }\end{array}$ & $\begin{array}{l}\text { Cast or forged implants with sufficient mechanical strength for } \\
\text { load-bearing orthopaedic applications } \\
\text {. Usually better than additive manufactured implants }\end{array}$ & $\begin{array}{l}\text { - Better than cast implants and can approach the strength } \\
\text { of forged implants }\end{array}$ \\
\hline $\begin{array}{l}\text { Design } \\
\text { complexity }\end{array}$ & $\begin{array}{l}\text { The design has to consider the manufacturing constraints related } \\
\text { to machining or casting at every step, so the implant design } \\
\text { should not be so complex and complicated that it cannot be } \\
\text { manufactured. }\end{array}$ & $\begin{array}{l}\text { Design freedom of complex geometries allows porous } \\
\text { scaffold and solid parts to integrate into one implant. } \\
\text { The porous scaffold has to be open cell to enable non- } \\
\text { melted metal powder to be removed. }\end{array}$ \\
\hline Porosity & $\begin{array}{l}\text { Difficult in machining application because it relies on a laser } \\
\text { taking material away from a solid part or a secondary material } \\
\text { being applied } \\
\text { Problem of stress shielding }\end{array}$ & $\begin{array}{l}\text { Porosity can be built into the design and accurately } \\
\text { fabricated. } \\
\text { - Reduce stiffness to match the modulus of surrounding } \\
\text { bone structure and minimise stress shielding }\end{array}$ \\
\hline Osseointegration & $\begin{array}{l}\text { Modify implant surface by secondary procedures like porous } \\
\text { surface coating, plasma spray hydroxyapatite coating }\end{array}$ & $\begin{array}{l}\text { Interconnected open porous structures with optimised } \\
\text { pores size and porosity }\end{array}$ \\
\hline $\begin{array}{l}\text { Post-processing } \\
\text { steps }\end{array}$ & - Milling, finishing, labelling, cleaning and sterilising & - Same as traditional implants \\
\hline Implant size & $\begin{array}{l}\text { Standardized and approximated to patients' geometry } \\
\text { Patients fit the implant, and necessary adjustments (bone } \\
\text { trimming) are performed during the surgical procedure. }\end{array}$ & $\begin{array}{l}\text { - Customize to the patient's bone defect and location } \\
\text { - Appropriate adjustments are minimal during the surgical } \\
\text { procedure. }\end{array}$ \\
\hline $\begin{array}{l}\text { Regulatory } \\
\text { requirements }\end{array}$ & $\begin{array}{l}\text { Regulatory standards related to the manufacturing quality } \\
\text { assurance are available. }\end{array}$ & $\begin{array}{l}\text { Regulatory standards are currently limited to ensure that } \\
\text { AM implants are safe and effective. }\end{array}$ \\
\hline $\begin{array}{l}\text { Clinical } \\
\text { applications }\end{array}$ & $\begin{array}{l}\text { Standard off-the-shelf implants with different sizes to serve the } \\
\text { bulk of the patient population } \\
\text { - Greater flexibility during the surgical procedure } \\
\text { - Long-term clinical evidence is available to support the implants } \\
\text { are safe and effective. }\end{array}$ & $\begin{array}{l}\text { - Limited to the patients as a "one-off" implant when a } \\
\text { standard off-the-shelf implant cannot address the } \\
\text { surgical requirements } \\
\text { - Less flexibility during the surgical procedure } \\
\text { - Only short-term, small number case series are available to } \\
\text { assess the clinical results of the implants. }\end{array}$ \\
\hline
\end{tabular}

alloy is the main material chosen for implants with cementless fixation. For loaded-bearing orthopaedic implants, the strength of pure titanium is not sufficient, and titanium alloys are preferred due to their better mechanical properties [24]. As the alloy has poor resistance against abrasive wear, it cannot be used for the articulating components in a joint replacement. The Ti-6Al-4V alloy is the most commonly used material for additive manufacturing of orthopaedic implants. However, one potentially hazardous issue in manufacturing titanium implants is that titanium metal is very reactive especially when it is heated up. It can react with oxygen and hydrogen, causing a spark or even explosion. Therefore, every mechanical work that will heat up the material, like casting, welding, additive manufacturing but also turning and milling, should be done with great caution and typically requires special preventive measures and procedures.

CoCrMo cast (ISO5832-4) or wrought alloys (ISO583212) are widely used for orthopaedic prosthetic implants. The alloys exhibit high mechanical strength and biocompatibility, corrosion resistance and excellent wear resistance against abrasive wear $[25,26]$. The high hardness of the material and the excellent material qualities allow polishing components to optical or mirror-like finishes. Therefore, CoCrMo alloys are the materials of choice for highly surface polished components such as femoral stems in hip replacements and femoral condyles in knee replacements. Other applications include acetabular cups and tibial trays in which mechanical strength 
is essential as the components are heavily loaded in the articulating joints and subject to fatigue. The alloy is the standard material for orthopaedic prosthesis fixed with bone cement. CoCr alloy powder for EBM (ASTM F75 CoCr, Arcam EBM, Sweden) has been available on the market [27]. The manufactured parts after heat treatment and machining demonstrate excellent implant qualities.

Steel-based alloys are not commonly used for prosthesis due to poor corrosion resistance. It may only be chosen for fracture implants like nails or plates that do not need to last in a human body as long as in joint prostheses.

The decision on choosing a particular metal material for additive manufacturing of an orthopaedic implant is not different from the conventional production process. It is not the manufacturing process that determines the choice of the metal material but the necessary properties of the orthopaedic implant required by the patient's surgical condition.

\section{Metal additive manufacturing systems for orthopaedic implants}

The two main powder-based fusion technologies of metal additive manufacturing, namely electron beam melting (EBM) and selective laser melting (SLM) are currently used for fabricating orthopaedic implants. Both techniques utilise a high temperature directed energy source (an electron beam or a laser beam) to melt and bond a thin layer $(20-200 \mu \mathrm{m})$ of fine metal powders in a computercontrolled pattern according to the computer-aided design (CAD) data of the implants. The layer having the shape of the cross-section of the implant then cools and bonds to the previous layer. Selected regions of metal powder are thus bonded layer by layer until the required metal implant is completely built. The implants are produced in clean environment chambers. The non-melted metal powders are not wasted and can be recycled for further use.

SLM works with a laser beam that transfers the melting energy to the metal powder. Scanning mirrors control the beam to the desired point on the powder bed of the build platform. As the mirrors are controlled mechanically, every redirection of laser beam needs time for the movement of the mirror. In EBM, an electron beam is adjusted by a magnetic field without any mechanical tools. Therefore, EBM technology is faster and more effective in producing the parts. As the heated metal powders, with specifications equivalent to the usual ISO5832 standards without any additives, melt and bond together, the density of SLM and EBM parts can reach to more than 99\%. Post manufacturing process like hot isostatic pressure (HIP) can increase the density to nearly $100 \%$.

Currently, EBM technology dominates the field of metal additive manufacturing in orthopaedic implants. One reason is that EBM takes place in a vacuum chamber instead of an inert gas-filled chamber in SLM. Even in an inert gas environment, Titanium alloy may pick up hydrogen especially at elevated temperatures during SLM. The hydrogen interaction with titanium alloys will affect the microstructure and composition, leading to the embrittlement and detrimental effects on mechanical properties of the AM implant [28]. The optimal mechanical properties of the implants can only be remedied by complex heat treatment. On the other hand, EBM parts are more "ready to use" after leaving the build chamber with regards to their mechanical properties. Although hydrogen embrittlement can also happen in various metal materials like steel or copper, titanium is very reactive and causes more related problems. Currently, as EBM has a faster-built rate, does not need heat treatment and less expensive than SLM, EBM seems to be more cost efficient in fabricating orthopaedic implants than SLM. The comparison of EBM and SLM technology in fabricating orthopaedic implants is shown in Table 2 [18,29-32].

\section{FEATURES OF AM ORTHOPAEDIC IMPLANTS}

Additive manufacturing enables unique features of orthopaedic implants that cannot be fabricated by conventional manufacturing methods including freeze casting and sintering. The conventional methods may address some of the complex bone geometries but have difficulty in fully adapting to the host bone due to mismatch in microstructure, mechanical and physical properties. Additive manufacturing has the advantage of design freedom and flexibility to create a patient-specific implant. In general, the success of an AM orthopaedic implant depends on not only its physical and mechanical properties but also the integration of interconnected pores into the design that promotes vascularisation with efficient exchange of nutrients and wastes required for normal cell proliferation and differentiation [33]. In this regard, additive manufacturing may customize an implant that 1) matches with the patient's bone anatomy and defect by using CT scan data of the patient's bone; 2) gives mechanical properties mimicking those of the host bone with sufficient strength for load-bearing applications and similar elastic modulus to minimize stress shielding and subsequent bone resorption; and 3) provides $3 \mathrm{D}$ scaffolds with interconnected porosity and pore 


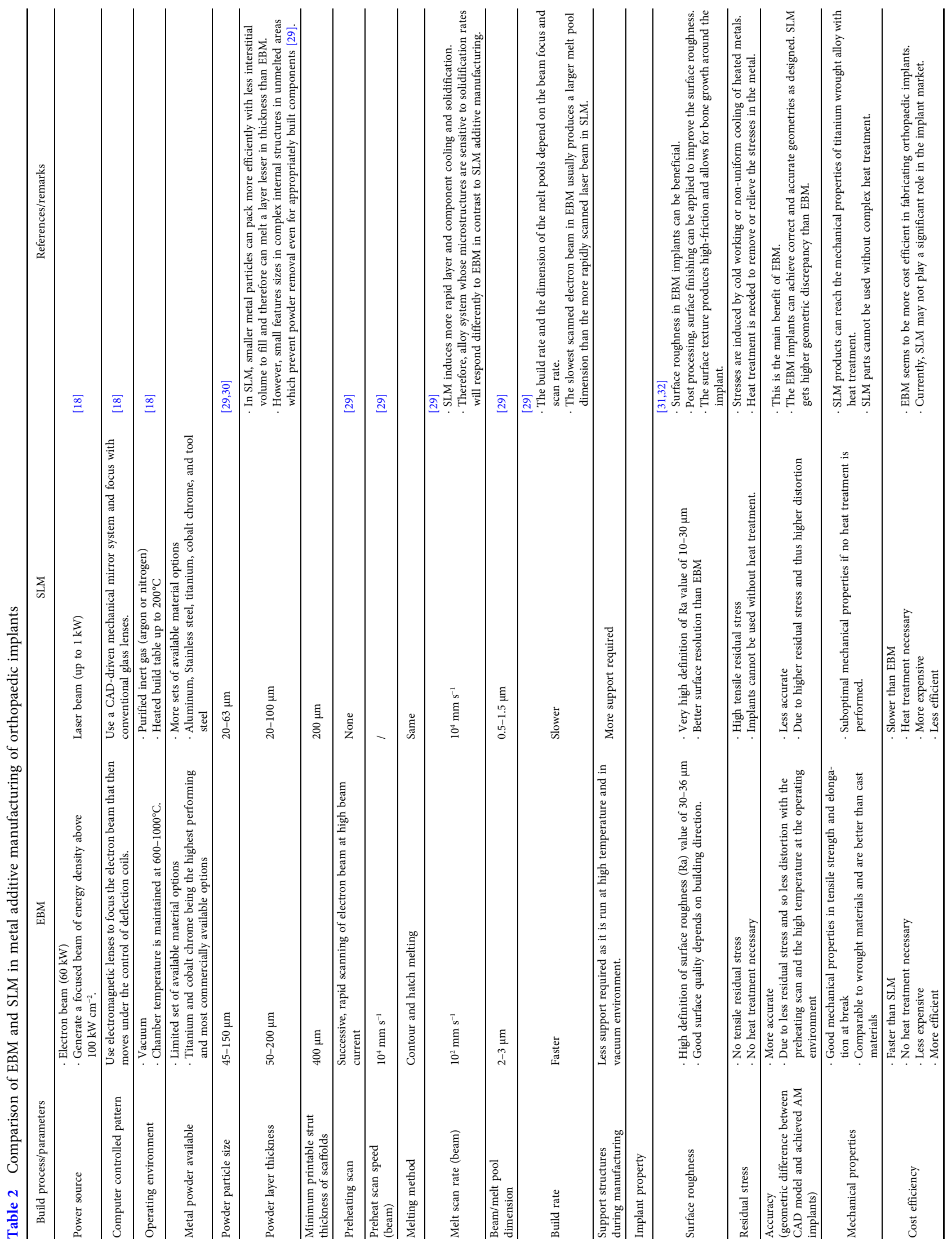


size optimal for bone ingrowth with mechanical interlocking for long-term implant fixation.

For an interconnected porous scaffold, the pore size is essential for optimal bone ingrowth, which has been reported in the range of $200-400 \mu \mathrm{m}[33,34]$. Pores of the diameter of $100-350 \mu \mathrm{m}$ are suitable for cell colonisation and vascularisation $[33,35]$. The size range also facilitated cells migration in porous scaffold and promoted bone regeneration [36]. On the other hand, a porous scaffold with pore sizes $<100 \mu \mathrm{m}$ is unfavourable for bone regeneration and leads to fibrous tissue or unmineralized woven bone formation as pore sizes of $\sim 5-15 \mu \mathrm{m}$ were only suitable for growth of fibroblasts [37], $\sim 70-120 \mu \mathrm{m}$ for chondrocytes [38]. For bone ingrowth, the minimum interconnected porosity of the scaffold should be at least $40 \%$ for sufficient cell infiltration [39]. High porosity can reduce the scaffold stiffness and thus stress shielding to the surrounding bone. Studies have shown that Ti-6Al$4 \mathrm{~V}$ scaffold gave a lesser stress shielding compared to solid samples of the same dimensions [40]. However, increase in porosity of the scaffold also compromises its mechanical properties that are not optimal for loadbearing orthopaedic applications. Compressive testing was conducted on five cellular Ti-6Al-4V samples fabricated using EBM [41]. It was found that these Ti-6Al-4V samples with $\sim 66 \%$ porosity had a maximum compressive strength of $116 \mathrm{MPa}$ and elastic modulus of $2.5 \mathrm{GPa}$ which are comparable to the mechanical properties of human cancellous bone [41]. The study demonstrated that EBM-fabricated Ti-6Al-4V parts with controlled internal pore architecture could meet the functional requirements of orthopaedic implants. A recent study was conducted to identify feasible design limit by assessing the interplay between mechanical properties, bone ingrowth requirements (pore size and porosity) and manufacturing constraints (strut thickness) [42]. 40 samples of selected porosities were fabricated using SLM. Mechanical compression testing was used to obtain stiffness and strength properties, whereas bone ingrowth was assessed in a canine in vivo model. The result showed the occurrence of bone ingrowth into high-strength porous biomaterials which have higher structural efficiency than current porous biomaterials in the market [42].

Functionally graded materials (FGM) parts have also been proposed to address the stiffness mismatch between the host bones and implants [43,44]. FGM parts are heterogeneous objects with material composition and microstructure that change gradually with positions within the parts $[43,44]$. Instead of homogeneous porosity throughout the entire structure, the porosity can be functionally graded and varied to match the porosity of adjacent bones after implantation. Therefore, additive manufacturing permits the creation of implants with complex geometries with a gradient of porosity perpendicular to the longitudinal axis of the implant, which allows the possibility of selecting the distribution of properties to achieve the desired biomechanical functions.

Titanium scaffolds with appropriate porous macro and microstructure were shown to have intrinsic osteoinductive ability without the need of additional osteogenic cells or osteoinductive agents $[45,46]$. Another recent study concurred with the findings. Hydroxyapatite (HA) coatings have been used to prompt osteogenesis without the need for additional osteogenic cells or bone morphogenic proteins (BMP) [45]. The results showed that HA coating to an AM porous titanium scaffold did not significantly increase osteogenicity in vitro and noncoated titanium scaffolds were also osteoinductive [47]. These scaffolds were then implanted in sheep femoral condyle. Extensive osteoinduction and osteointegration (70\% bone ingrowth) were observed in vivo, confirming the intrinsic capacity of the produced porous titanium scaffolds for bone regeneration [47].

Therefore, the current evidence supports that additive manufacturing allows the fabrication of an implant with complex geometries matching to the patient's bony anatomy, and the combination of both porous scaffolds for osseointegration $[48,49]$ and rigid parts for physiological load transfer [50] (Fig. 1a, b).

To further accelerate and enhance bone ingrowth, a thin bioactive calcium phosphate coating can be deposited on the surface of AM porous scaffolds [51] (Fig. 2). Smooth surfaces can be added to a particular part of the implants to reduce potential soft tissue irritation [11]. Also, the high design freedom allows plates and screws fixation to be added to a single piece of the AM titanium implant (Fig. 1a, b). It ensures an initial stable fixation at the good bone stock areas of the operative sites while secondary bone ingrowth into the porous scaffold takes place to increase implant longevity.

Designers and manufacturers need to take into account the cleaning requirements of the implants at the design stage. Parts with porous scaffolds pose a greater challenge. The pores must be interconnected, open and large enough (size $>20 \mu \mathrm{m}$ in practice) to allow non-melted metal powder to be removed. Also, the process of cleaning the residue debris and removing unwanted support material has to be safe and reproducible. Meanwhile, special tools like ultrasonic cleaners are available, but systems and 

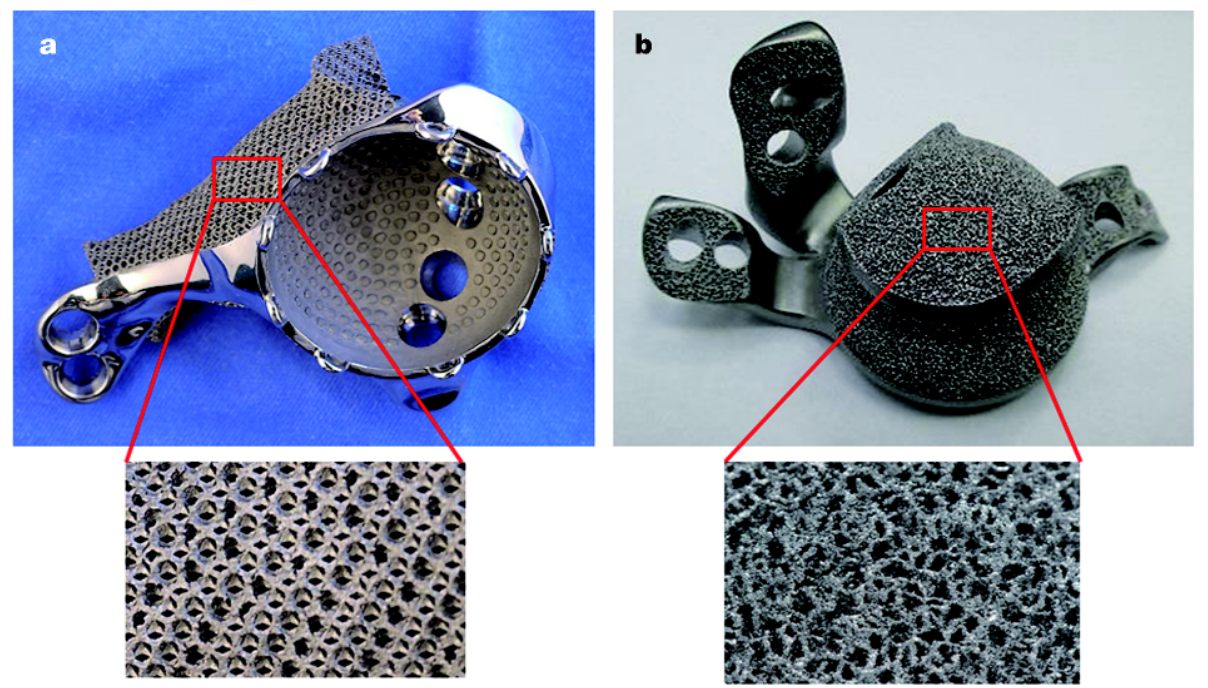

Figure 1 (a) A 3D-printed patient-specific acetabular tumour implant with a porous scaffold to fill up the bone defect after tumour resection, an acetabular cup for hip joint articulation, screw holes for bone fixation and anterior smooth surface to minimise soft tissue irritation. The average pore size is $720 \mu \mathrm{m}$. (The implant was designed and manufactured by Mobelife, Materialise, Belgium). (b) A 3D-printed patient-specific revision acetabular cup with a porous scaffold to fill up the bone loss, an acetabular cup for hip joint articulation, flanges and screws for stabilisation and bone fixation. The pore size ranges from 100 to $500 \mu \mathrm{m}$. The implant was designed and manufactured by Implantcast GmbH, Germany.

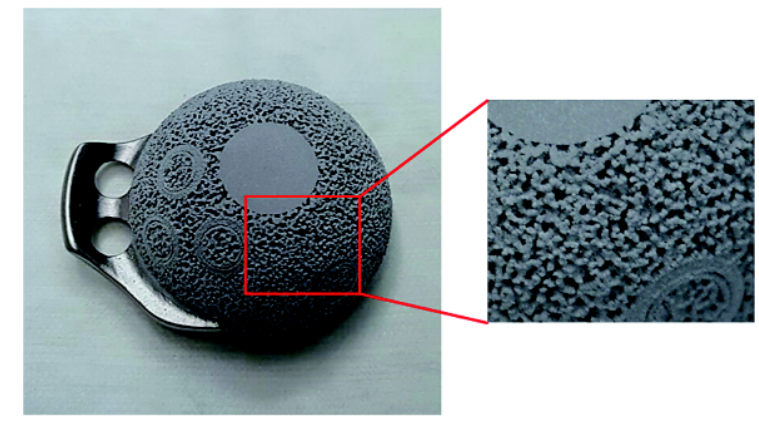

Figure 2 A 3D-printed patient-specific acetabular cup for an eightyear-old boy. No off-the-shelf, standard sized implant fitted the small pelvic bone. Flanges were added for better stability and screws were designed in an orientation to avoid injury to triradiate growing cartilage. The magnified view shows the porous surface of the implant is coated with calcium phosphate that fastens and further improves osseointegration. The implant was designed and manufactured by Implantcast GmbH, Germany.

processes need to be established and regularly monitored.

\section{THE PROCESS CHAIN OF AM ORTHOPAEDIC IMPLANTS}

The process chain for $3 \mathrm{D}$ printed customised orthopaedic implants is shown in Fig. 3a-g. The process steps in powder-bed based 3D printing include:

1) $3 D$-CAD: The implant is first designed in $\mathrm{CAD}$ software, based on the data of patient's CT images, the surgical requirement of the implant and the production method employed. Different designs need different production methods. The design rules and constraints vary by the selected production method.

2) Slicing: The $3 \mathrm{D}$ implant CAD file is then transferred into build preparation software, in which the $3 \mathrm{D}$ CAD model is virtually sliced into individual layers, each of which corresponds to the layer thickness of the $3 \mathrm{D}$ printing.

3) Powder application: a powder layer is evenly applied using a blade system on the lifting table. The height of the powder layer corresponds to the slice thickness previously generated at the CAD model and is in the order of $50 \mu \mathrm{m}$ (Fig. 4a). An AM implant with a layer thickness of $50 \mu \mathrm{m}$ has a good balance between the achieved surface roughness and cost efficiency of the manufacturing process.

4) Melting: An electron beam or a laser beam melts the particular areas of metal powders of the layer according to the computer pre-defined paths. The melted powder having the shape of the cross-section of the implant then cools and solidifies. During subsequent cycles, the same process is repeated and the melted powder of the most recent layer bonds with those formed during previous cycles (Fig. 4b).

5) Lowering: After melting particular regions of this slice, the table is lowered by $50 \mu \mathrm{m}$, and another slice of powder is placed on the table. After that, the next melting cycle takes place. This procedure is repeated until the table is completely lowered and the final implant is built. Building time depends on the size of the implant and can 
a

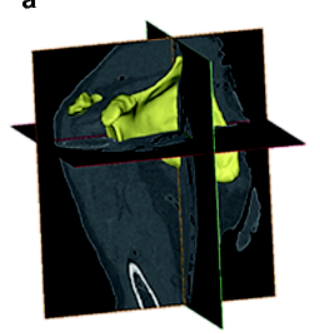

CT/MR scan

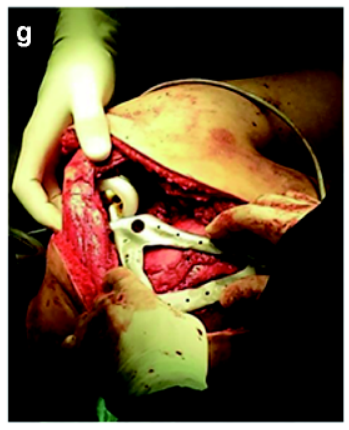

Surgical application b

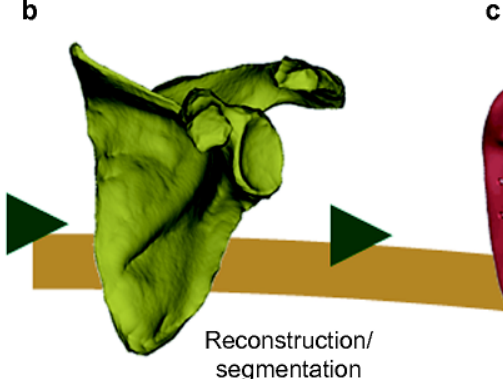

segmentation
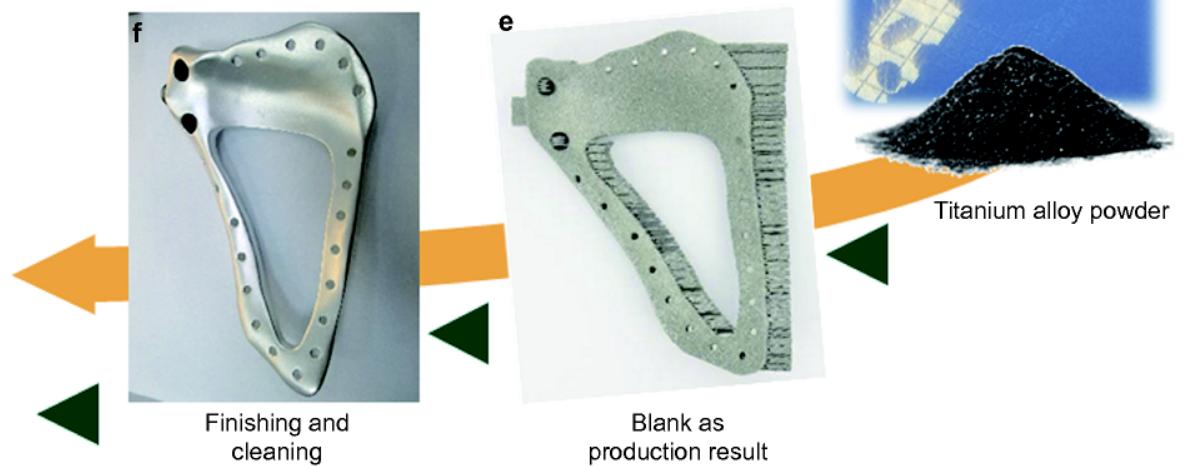

Figure 3 The process chain of using a 3D-printed patient-specific implant in a patient undergoing scapular tumour resection and reconstruction. (a) CT/MR images were acquired. (b) The region of interest, the scapular bone was segmented. (c) A patient-specific scapular tumour implant was designed by CAD software, based on the patient's medical imaging data. (d) The implant was 3D-printed layers by layers by melting and bonding titanium alloy powder under high energy beam. (e and f) Constructs supporting the 3D-printed were removed, and the implant surface was finished and cleaned. (g) The implant was sterilised and placed at the operating theatre.

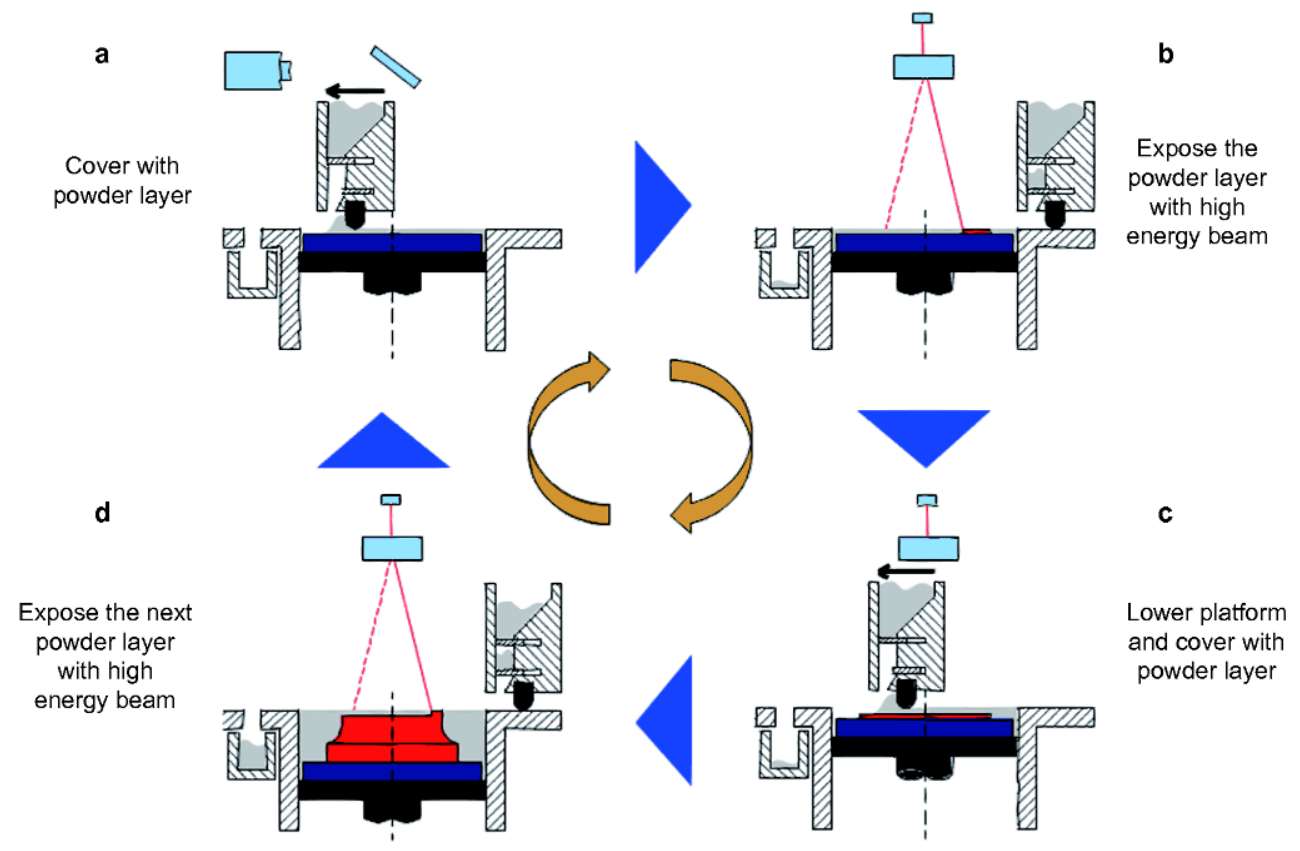

Figure $4(a-d)$ shows the process steps in powder-bed based 3D printing of metallic implants using Electron Beam Melting or Selective Laser Melting techniques. 


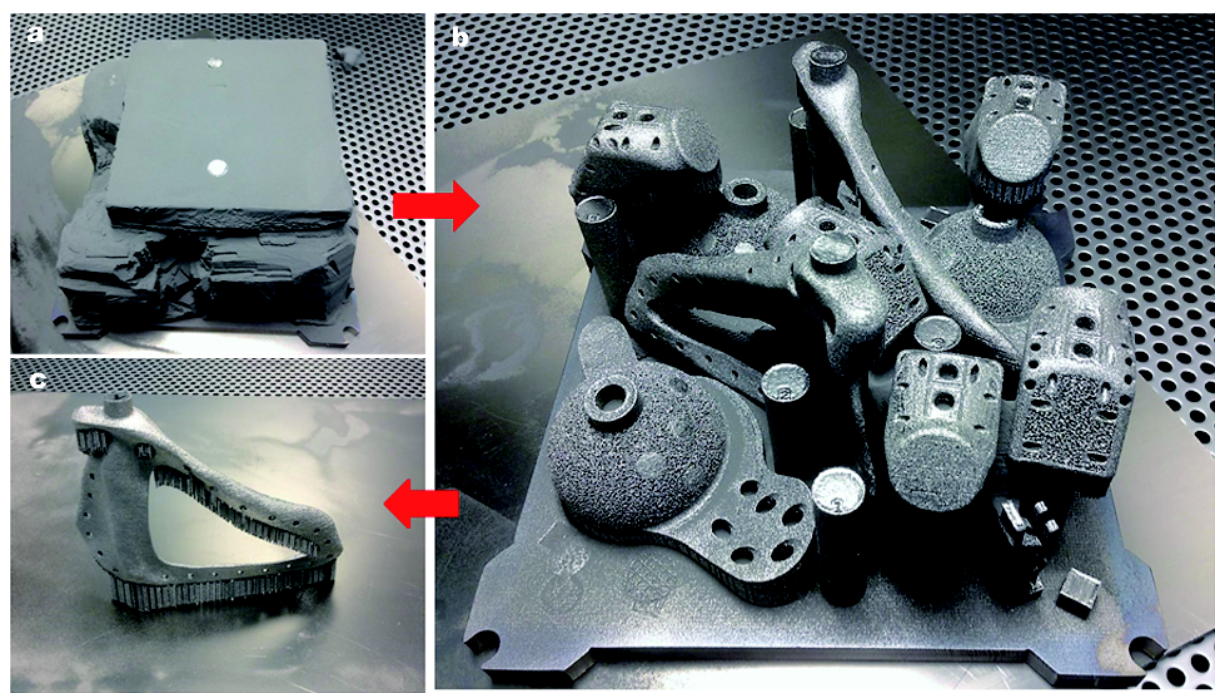

Figure 5 (a) A block of metal powdered build material was removed from the chamber of 3D printing machine after cooling. It contained both the 3D-printed implants and the non-melted build metal powder that also acted as a support for the implant. (b) After the unused metal powder was removed, the same batch of various shaped 3D-printed implants can be further processed. (c) A scapular implant. Support structures (the small vertical bars) are needed to hold the hollow parts of the 3D-printed implant from succumbing to gravity or keep the whole implant anchored to the print bed, so it does not curl up on itself.

take 8 to 36 h (Fig. $4 \mathrm{c}, \mathrm{d})$.

6) Component removal: The component is within the non-melted titanium powder and can be taken out of the chamber after cooling (Fig. 5a-c). The unused powder is recycled for future use.

The turnaround time takes about 20 to $48 \mathrm{~h}$, and it depends on how many implants are built at the same time in the batch. AM parts are built and anchored to the build platform. Although additive manufacturing eliminates many geometric constraints of the traditional method, some limitations on the design of an AM implant have to be considered. It is less favourable to manufacture large metal blocks because of problems of cooling down of the heated metal. Very fine structures that are smaller than the grain size of the metal materials cannot be fabricated. The porous scaffolds have to be interconnected and open cell to allow non-melted metal powder to be removed. Correct supports are added to the built geometry to prevent thermal stress from warping or shrinking the parts [52]. Metal additive manufacturing in vacuum chambers prevents titanium alloys from interacting with oxygen and hydrogen especially at high temperature during the melting process of additive manufacturing. Air polluted environment may lead to brittle products that cannot be used. With the current additive manufacturing technology, the density of a rigid part of an orthopaedic implant can be over $99 \%$. Secondary heat treatment processes such as hot isostatic pressing can give stronger parts with $100 \%$ density and complete removal of pores inside. Post procession steps like milling, finishing, labelling, cleaning and sterilising the implants are the same as in the conventional implant manufacturing, and the additive manufacturing portion of an implant production is only a small, yet important part of the whole process. Therefore, the time required for manufacturing an AM patient-specific implant is not particularly less than that for a conventionally manufactured implant.

\section{CLINICAL APPLICATIONS OF AM ORTHOPAEDIC IMPLANTS}

In general, mass-produced implants fabricated by conventional methods can effectively serve the bulk of the patient population. However, when the mass-produced implants do not fit the clinical scenarios, like bone cancer surgery and, severe bone loss in revision joint surgery, surgeons are forced to fit the implants to the patient's anatomy by unnecessary bone removal and other additional surgical procedures to build up the bone loss. With the versatile design and manufacturing in additive manufacturing, patient-specific designed implants may be fabricated to match a patient's unique geometry of a bone defect that is not available in mass-produced form. Therefore, the AM implants may reduce the operating time in reconstructing the complex bone defects. It minimises the impact that the surgery needs to have on the surrounding tissue and shortens the recovery time of 


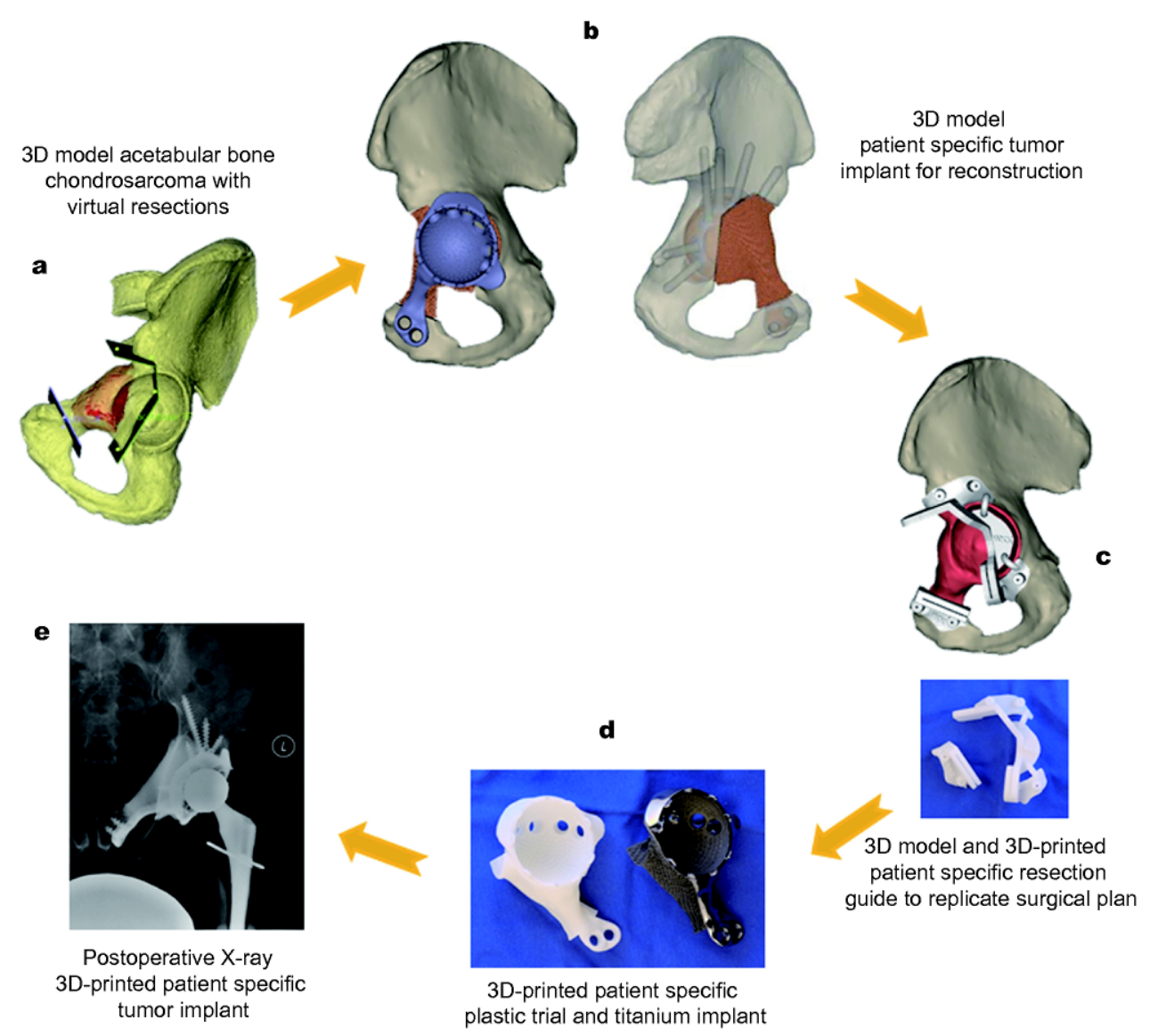

Figure 6 The workflow of a 3D-printed patient-specific tumour implant in a patient with left acetabular malignant bone tumour (chondrosarcoma) undergoing tumour resection and reconstruction.

the patient after the surgery. Additionally, additive manufacturing allows the porous structure to be integrated into the design at the time of its manufacture. It is in contrast to the conventional manufacturing process in which adding porosity is a secondary procedure and is restricted to a predetermined structure with limited shapes and porosity of the designed metal. This is very advantageous in a complex surgery with varying amounts of bone loss. AM implants not only can match the specific bone geometry, but also may be optimised in design to match the microscopic 3D structure with desired porosity and stiffness at the surgical sites that are best for bone ingrowth and long-term implant fixation.

To date, there are only a few publications on the clinical use of AM patient-specific implants. The early case series are encouraging in various field of complex orthopaedic procedures, like bone tumour surgery [8-10,14], revision hip surgery $[6,7,11]$, spinal implants $[12-14]$ and trauma fracture fixation and reconstruction $[15,16]$. The additive manufacturing technology may address the reconstructive challenges that off-the-shelf, standard implants cannot provide for implant-size or disease-specific surgical requirement.

In bone sarcoma surgery, tumour resection results in unique bone defects that often require reconstruction to restore the skeletal continuity and function (Fig. 6a-e). AM metallic implants have the great potential to customise the reconstructive needs at various locations of patients' skeleton. AM patient-specific implants have recently been applied for reconstruction in clavicular, scapular, calcaneal, pelvic and sacral bone tumours, which have complex bony geometry and no off-the-shelf implants available for bone reconstruction $[8-10,14]$. A case series of three patients with clavicle, scapular and pelvic bone sarcoma underwent tumour resection, and the bone defects were reconstructed with EBM fabricated titanium prostheses. With a clinical follow-up of 21-48 months, all patients had satisfactory limb functions, and there were no reported surgical complications including limb length discrepancy, screw loosening, and implant breakage. It 


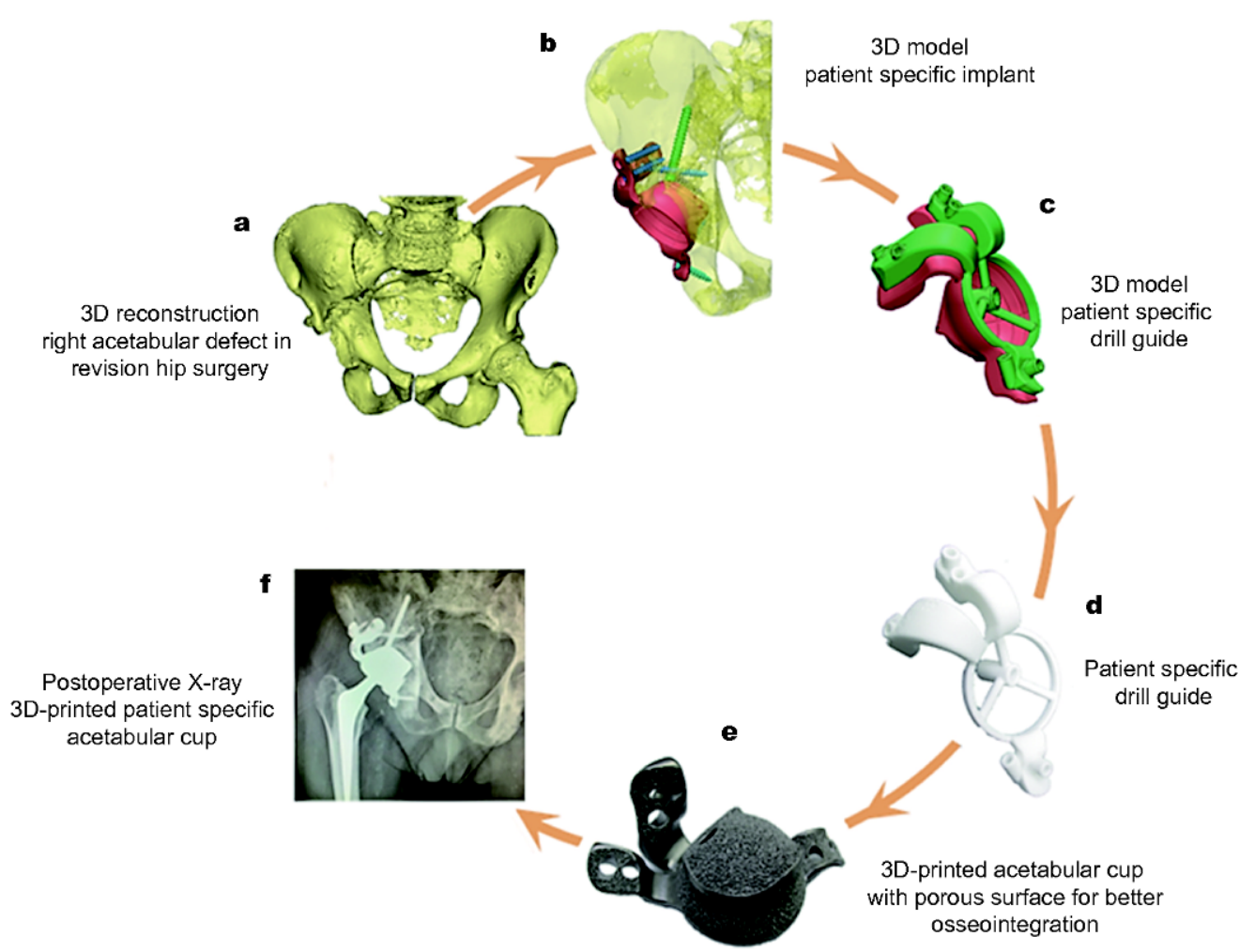

Figure 7 The workflow of a 3D-printed patient-specific acetabular implant in a patient with the loosening of previous hip implant undergoing revision hip surgery.

might improve the effectiveness of limb-saving surgery for sarcomas in unusual sites [8]. A series of 35 patients underwent resection of a pelvic tumour and reconstruction using AM tumour prostheses. As the pelvis is a highly load-bearing area, the porous surface was designed and fabricated at the implant-bone junction to facilitate bone ingrowth. The study concluded that additive manufacturing could promote the precise matching and osseointegration between implants and the host bone. The AM prosthesis for reconstruction of the bony defect after resection of a pelvic tumour was safe, without additional complications, and gave good short-term functional results [53]. Therefore, AM tumour implants may be an ideal option to accurately reconstruct the unique anatomy of any patients with specific bone defects in bone sarcoma surgery. Plates and screws can be customised to ensure the initial stable implant fixation while the porous scaffold promotes osseointegration to the host bone to provide the long-term stability of the implant. Also, the porosity of the implant can be optimised to reduce the modulus and the stiffness of the implants that more closely matches bone. It may minimise stress shieldingrelated implant loosening $[8,10]$. Assistive tools such as computer navigation or patient-specific guides may be required to replicate the surgical plans and achieve a good fit of the implants [17].

AM patient-specific implants have been reported as a valuable option in difficult revision hip arthroplasty as it may address severe acetabular bone loss or compromised biology such as irradiated bone [11]. The early clinical results of the new technique were satisfactory in limb function and implant alignment in two studies [6,7]. Patients' CT images were first analysed with reference to bone quality and geometry of the acetabular bone defects (Fig. 7a-f). The patient-specific titanium implant was then designed to fill up the bone loss with a porous augment and a correctly oriented acetabular cup for hip articulation. The implant could either be made as a monobloc component or in two parts as a modular construct. The implant was stabilised to the pelvic bone by flanges and screws with optimal purchase at the available areas with good bone quality. The cup screws were planned at safe trajectories to avoid injuries to nearby neurovascular structures. Associated drill guides were fabricated to assist surgeons to insert the screws correctly. AM implants were recently reported in hip 
replacement for severe hip deformities [54]. 57 cases undergoing conventional hip arthroplasties were compared with 17 cases undergoing AM hip arthroplasties. The results showed the time to postoperative weightbearing, and functional scores of the patients in AM group were better than those in the conventional group. However, the postoperative infection and loosening rates were higher in the AM group.

The AM spinal implants have been recently reported in the treatment of upper cervical spine (C1/2) fusion [12], complex spinal pathologies such as craniocervical junction tumour or complex spinal congenital deformity [13] and sacral tumour resection [14]. The patient-specific fixation device allowed pre-determined depth and orientation of the screw path, based on the preoperative CT-based 3D planning [12]. The implant not only reduced the overall operative time but also improved the safety with a reduced risk of neurovascular injury. Patient-specific implants matching the vertebral bone defects with built-in fixation facilitated the surgery as it avoided further complex reconstruction like harvesting rib or fibular grafts and the intraoperative fashioning of these grafts to fit the defects $[13,14]$.

Treatment of complex acetabular fracture and posttraumatic skeletal deformities and defects may also benefit from this technology $[15,16]$. Patient-specific titanium plates were additive manufactured that could be customised to both the shape of the pelvis and the type of acetabular fracture [15]. It saves the operative time to contour the standard-sized plates to the local anatomy that is sometimes difficult. AM titanium truss cages have been utilised to address the complicated problem of segmental bone loss often associated with posttraumatic limb deformities [16]. The truss construct has the lattice for bone graft placement to facilitate bone ingrowth. Conventional intramedullary locking nails or plates can also be incorporated into the design of the truss cages for stable bone fixation. Therefore, the implants are mechanically stable with the least mass that allows immediate weight-bearing movement.

The advanced design of an AM implant can include the virtual biomechanical simulation using patient-specific modelling and finite element analysis to evaluate the implant performance [10,55]. It may optimise and modify the design of the implant before the actual fabrication. It may assist surgeons in providing the best-personalised implant for an individual patient. Use of AM patientspecific implants requires close collaboration between orthopaedic surgeons and biomedical implant engineers. While planning the implants, engineers have to design, based on the surgeons' comments on the surgical requirements that include the surgical approach, the bone defects to be reconstructed, the optimal alignment of implants needed to achieve, sites of bone fixation and porous scaffold for bone ingrowth. Therefore, the desired geometry of the implant not only can be fabricated by additive manufacturing but also possesses the required mechanical and physical properties for surgical applications. The effective collaborative work between surgeons and engineers needs to be established with time and will improve with ongoing advances in the technology.

\section{CHALLENGES FOR AM IMPLANTS}

Although AM implants offer great promise due to their ability to address reconstructive challenges that are beyond the scope of off-the-shelf standard implants, a few barriers that limit this emerging technology from becoming commonplace should be noted $[12,17,56]$.

The first hurdle to clear is demonstrated clinical performance. Similar to any other new surgical technologies at the early introduction phase, the long-term clinical results of using AM implants in comparison to traditional techniques lacks in orthopaedic applications. It remains to be seen whether the acknowledged potential advantages of the technology can translate into better patients' clinical outcome [17]. The design and fabrication of $\mathrm{AM}$ implants require $3 \mathrm{D}$ engineering software and specialised skills that most surgeons do not have [56]. High implant cost due to its single customised use, the software and machine investment further hinders the popularity of using the new technology among orthopaedic surgeons. Careful clinical research is needed to prove safety, clinical effectiveness, and cost-effectiveness for patients, surgeons, and payers alike.

Secondly, there are some regulatory concerns in the design and manufacturing of AM implants for clinical applications as there are currently limited regulatory standards that ensure safe and effective AM implants $[12,57]$. The design of an AM patient-specific implant is based on the patient's anatomy and clinically proven designs that address the user needs. Validation of the results of these implants can only be done after their implantation. Prospective studies have limitations as one cannot compare different patient-specific implants in different patients. The design of the AM implants and the accuracy of the planning process may be validated by comparing the postoperative CT scan with the preoperative design planning. However, this is normally not performed because of unnecessary radiation exposure during the acquisition of $\mathrm{CT}$ images. The clinical per- 
formance of an AM patient-specific implant can only be partly validated by comparing the retrospective results of the patients treated by implants with similar design features. Therefore, the current use of AM patient-specific implants is limited to the patients when a standard offthe-shelf implant cannot address the surgical requirements. Regulatory considerations should include 1) the design control (from design input, design process to design output) at the pre-additive manufacturing stage, 2) raw materials, technical process to ensure consistency between builds and post-manufacture quality assurance at the additive manufacturing stage, and 3) cleaning, finishing, biocompatibility and sterilization at the post-additive manufacturing stage [58].

As the current workflow of AM implants requires various software and steps from the acquisition of preoperative medical imaging to the final implant fabrication, most orthopaedic surgeons are unfamiliar and not easily master the process. An integrated unified computer platform should be developed to allow easy planning and seamless communication among different care providers like radiologists, orthopaedic surgeons, engineers, and implant companies [17]. It may increase the utilisation of additive manufacturing technology among orthopaedic surgeons in the future.

\section{CONCLUSION}

The advent of additive manufacturing technology is opening up many opportunities in patient-specific orthopaedic applications. Metal additive manufacturing is used to manufacture both patient-specific implants and mass-produced orthopaedic implants. Besides being anatomically conformed to a patient's anatomy and surgical requirement, AM implants can incorporate porous scaffolds and solid component into one monobloc with reduced implant stiffness and facilitate osseointegration. Lack of long-term superior clinical results, the need for special engineering skills and no standard regulations are some concerns for the development of additive manufacturing in orthopaedic implants. With further advances in the technology and reduced cost, additive manufacturing may allow efficient, on-demand production of patient-specific body parts with optimised properties that meet the biological and structural needs of the individual patient for orthopaedic applications.

\section{Received 31 October 2017; accepted 6 March 2018; published online 22 March 2018}

1 Neal ML, Kerckhoffs R. Current progress in patient-specific modeling. Briefings Bioinf, 2010, 11: 111-126
2 Laine T, Lund T, Ylikoski M, et al. Accuracy of pedicle screw insertion with and without computer assistance: a randomised controlled clinical study in 100 consecutive patients. Eur Spine J, 2000, 9: 235-240

3 Anderson KC, Buehler KC, Markel DC. Computer assisted navigation in total knee arthroplasty. J Arthroplasty, 2005, 20: 132-138

4 Wong KC, Kumta SM. Computer-assisted tumor surgery in malignant bone tumors. Clin Orthop Rel Res, 2013, 471: 750-761

5 Wong KC, Kumta SM, Sze KY, et al. Use of a patient-specific $\mathrm{CAD} / \mathrm{CAM}$ surgical jig in extremity bone tumor resection and custom prosthetic reconstruction. Comput Aided Surgery, 2012, 17: 284-293

6 Colen S, Harake R, Haan JDE, Mulier M. A modified custom-made tri-flanged acetabular reconstruction ring (MCTARR) for revision hip arthroplasty with severe acetabular defects. Acta Orthop Belg, 2013, 79: 71-75

7 Baauw M, van Hellemondt GG, van Hooff ML, et al. The accuracy of positioning of a custom-made implant within a large acetabular defect at revision arthroplasty of the hip. Bone Joint J, 2015, 97-B: 780-785

8 Fan $\mathrm{H}, \mathrm{Fu}$ J, Li X, et al. Implantation of customized 3-D printed titanium prosthesis in limb salvage surgery: a case series and review of the literature. World J Surg Onc, 2015, 13: 308

9 Imanishi J, Choong PFM. Three-dimensional printed calcaneal prosthesis following total calcanectomy. Int J Surgery Case Rep, 2015, 10: 83-87

10 Wong KC, Kumta SM, Geel NV, et al. One-step reconstruction with a 3D-printed, biomechanically evaluated custom implant after complex pelvic tumor resection. Comput Aided Surgery, 2015, 20: $14-23$

11 Wyatt MC. Custom 3D-printed acetabular implants in hip surgery-innovative breakthrough or expensive bespoke upgrade? Hip Int, 2015, 25: 375-379

12 Phan K, Sgro A, Maharaj MM, et al. Application of a 3D custom printed patient specific spinal implant for $\mathrm{C} 1 / 2$ arthrodesis. J Spine Surg, 2016, 2: 314-318

13 Mobbs RJ, Coughlan M, Thompson R, et al. The utility of 3D printing for surgical planning and patient-specific implant design for complex spinal pathologies: case report. J Neurosurgery-Spine, 2017, 26: 513-518

14 Wei R, Guo W, Ji T, et al. One-step reconstruction with a 3Dprinted, custom-made prosthesis after total en bloc sacrectomy: a technical note. Eur Spine J, 2017, 26: 1902-1909

15 Merema BJ, Kraeima J, Ten Duis K, et al. The design, production and clinical application of 3D patient-specific implants with drilling guides for acetabular surgery. Injury, 2017, 48: 2540-2547

16 Tetsworth K, Block S, Glatt V. Putting 3D modelling and 3D printing into practice: virtual surgery and preoperative planning to reconstruct complex post-traumatic skeletal deformities and defects. SICOT-J, 2017, 3: 16

17 Wong KC. 3D-printed patient-specific applications in orthopedics. Orthop Res Rev, 2016, Volume 8: 57-66

18 Sing SL, An J, Yeong WY, et al. Laser and electron-beam powderbed additive manufacturing of metallic implants: A review on processes, materials and designs. J Orthop Res, 2016, 34: 369-385

19 International Organization for Standardization, ISO 5832:2016: Implants for surgery: metallic materials. https://www.iso.org/standard/66637.html

20 Balazic M, Kopac J, Jackson MJ, et al. Review: titanium and titanium alloy applications in medicine. IJNBM, 2007, 1: 3-34 
21 Pattanayak DK, Fukuda A, Matsushita T, et al. Bioactive Ti metal analogous to human cancellous bone: Fabrication by selective laser melting and chemical treatments. Acta Biomater, 2011, 7: 13981406

22 Rapuano BE, Lee JJE, MacDonald DE. Titanium alloy surface oxide modulates the conformation of adsorbed fibronectin to enhance its binding to a $5 \beta 1$ integrins in osteoblasts. Eur J Oral Sci, 2012, 120: 185-194

23 Olivares-Navarrete R, Gittens RA, Schneider JM, et al. Osteoblasts exhibit a more differentiated phenotype and increased bone morphogenetic protein production on titanium alloy substrates than on poly-ether-ether-ketone. Spine J, 2012, 12: 265-272

24 Ryan G, Pandit A, Apatsidis DP. Fabrication methods of porous metals for use in orthopaedic applications. Biomaterials, 2006, 27: 2651-2670

25 Sieber HP, Rieker CB, Köttig P. Analysis of 118 second-generation metal-on-metal retrieved hip implants. J Bone Joint Surgery, 1999, 81: $46-50$

26 Rieker C, Köttig P. In vivo tribological performance of 231 metalon-metal hip articulations. HIP Int, 2002, 12: 73-76

27 Arcam EBM, Metal Powders. http://www.arcam.com/technology/ products/metal-powders/

28 Tal-Gutelmacher E, Eliezer D. The hydrogen embrittlement of titanium-based alloys. JOM, 2005, 57: 46-49

29 Murr LE, Martinez E, Amato KN, et al. Fabrication of metal and alloy components by additive manufacturing: examples of $3 \mathrm{D}$ materials science. J Mater Res Tech, 2012, 1: 42-54

30 Song $\mathrm{B}$, Zhao X, Li S, et al. Differences in microstructure and properties between selective laser melting and traditional manufacturing for fabrication of metal parts: A review. Front Mech Eng, 2015, 10: 111-125

31 Wang P, Sin WJ, Nai MLS, et al. Effects of processing parameters on surface roughness of additive manufactured Ti-6Al-4V via electron beam melting. Materials, 2017, 10: 1121

32 Wang D, Liu Y, Yang Y, et al. Theoretical and experimental study on surface roughness of $316 \mathrm{~L}$ stainless steel metal parts obtained through selective laser melting. Rapid Prototyping J, 2016, 22: 706716

33 Karageorgiou V, Kaplan D. Porosity of 3D biomaterial scaffolds and osteogenesis. Biomaterials, 2005, 26: 5474-5491

34 Kumar A, Nune KC, Murr LE, et al. Biocompatibility and mechanical behaviour of three-dimensional scaffolds for biomedical devices: process-structure-property paradigm. Int Mater Rev, 2016, 61: 20-45

35 Shim JH, Kim SE, Park JY, et al. Three-dimensional printing of rhBMP-2-loaded scaffolds with long-term delivery for enhanced bone regeneration in a rabbit diaphyseal defect. Tissue Eng Part A, 2014, 20: 1980-1992

36 Sanz-Herrera JA, García-Aznar JM, Doblaré M. On scaffold designing for bone regeneration: A computational multiscale approach. Acta Biomater, 2009, 5: 219-229

37 Klawitter JJ, Hulbert SF. Application of porous ceramics for the attachment of load bearing internal orthopedic applications. J Biomed Mater Res, 1971, 5: 161-229

38 Griffon DJ, Sedighi MR, Schaeffer DV, et al. Chitosan scaffolds: Interconnective pore size and cartilage engineering. Acta Biomater, 2006, 2: 313-320

39 Bragdon CR, Jasty M, Greene M, et al. Biologic fixation of total hip implants. J Bone Joint Surgery, 2004, 86: 105-117

40 Harrysson OLA, Cansizoglu O, Marcellin-Little DJ, et al. Direct metal fabrication of titanium implants with tailored materials and mechanical properties using electron beam melting technology. Mater Sci Eng-C, 2008, 28: 366-373

41 Li X, Wang C, Zhang W, et al. Fabrication and characterization of porous Ti6Al4V parts for biomedical applications using electron beam melting process. Mater Lett, 2009, 63: 403-405

42 Arabnejad S, Burnett Johnston R, Pura JA, et al. High-strength porous biomaterials for bone replacement: A strategy to assess the interplay between cell morphology, mechanical properties, bone ingrowth and manufacturing constraints. Acta Biomater, 2016, 30: 345-356

43 Muller P, Mognol P, Hascoet JY. Modeling and control of a direct laser powder deposition process for Functionally Graded Materials (FGM) parts manufacturing. J Mater Proc Tech, 2013, 213: 685692

44 Bobbio LD, Otis RA, Borgonia JP, et al. Additive manufacturing of a functionally graded material from Ti-6Al-4V to Invar: Experimental characterization and thermodynamic calculations. Acta Mater, 2017, 127: 133-142

45 Fujibayashi S, Neo M, Kim HM, et al. Osteoinduction of porous bioactive titanium metal. Biomaterials, 2004, 25: 443-450

46 Fukuda A, Takemoto M, Saito T, et al. Osteoinduction of porous Ti implants with a channel structure fabricated by selective laser melting. Acta Biomater, 2011, 7: 2327-2336

47 Tamaddon M, Samizadeh S, Wang L, et al. Intrinsic osteoinductivity of porous titanium scaffold for bone tissue engineering. Int J Biomater, 2017, 2017: 1-11

48 Warnke PH, Douglas T, Wollny P, et al. Rapid prototyping: porous titanium alloy scaffolds produced by selective laser melting for bone tissue engineering. Tissue Eng Part C-Methods, 2009, 15: 115-124

49 Van der Stok J, Van der Jagt OP, Amin Yavari S, et al. Selective laser melting-produced porous titanium scaffolds regenerate bone in critical size cortical bone defects. J Orthop Res, 2013, 31: 792799

50 Yang S, Leong KF, Du Z, et al. The design of scaffolds for use in tissue engineering. Part I. Traditional factors. Tissue Eng, 2001, 7: 679-689

51 Reigstad O, Franke-Stenport V, Johansson CB, et al. Improved bone ingrowth and fixation with a thin calcium phosphate coating intended for complete resorption. J Biomed Mater Res, 2007, 83B: 9-15

52 3D printing and advanced manufacturing: Getting the most out of metal 3D printing: Understanding design \& Process controls for DMLS. Stratasys Direct Manufacturing. Accessed on Oct 22, 2017: https://www.stratasysdirect.com/content/white_papers/ DMLS_White_Paper_201509_v3.pdf

53 Liang H, Ji T, Zhang Y, et al. Reconstruction with 3D-printed pelvic endoprostheses after resection of a pelvic tumour. Bone Joint J, 2017, 99-B: 267-275

54 Wang S, Wang L, Liu Y, et al. 3D printing technology used in severe hip deformity. Exp Therap Med, 2017, 14: 2595-2599

55 Bartels W, Gelaude F, Delport H, Jonkers I, Sloten JV. Patientspecific Reconstruction of Large Bone Defects: Clinical Success Due to an Integrated Bioengineering Workflow. In: Kyriacou E, et al. (eds.), XIV Mediterranean Conference on Medical and Biological Engineering and Computing 2016, IFMBE Proceedings, 2016, 57: 659-662

56 Martelli N, Serrano C, van den Brink H, et al. Advantages and disadvantages of 3-dimensional printing in surgery: A systematic 
review. Surgery, 2016, 159: 1485-1500

57 Trace AP, Ortiz D, Deal A, et al. Radiology's emerging role in 3-D printing applications in health care. J Am College Rad, 2016, 13: 856-862.e4

58 Morrison RJ, Kashlan KN, Flanangan CL, et al. Regulatory considerations in the design and manufacturing of implantable 3Dprinted medical devices. Clinical Translational Sci, 2015, 8: 594600
Author contributions Wong KC proposed the paper and contributed to the work for the sections on introduction, clinical applications, limitations and future development. Scheinemann $\mathrm{P}$ contributed the engineering parts of the paper.

Conflict of interest Wong KC declares that he has no conflict of interest. Scheinemann P is the Director of Research and Development in Implantcast $\mathrm{GmbH}$ company, Buxtehude, Germany.

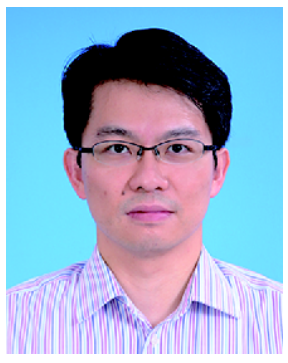

Kwok-Chuen Wong, MBChB, MD (CUHK) and FRCSEd (Ortho), has specialised in orthopaedic oncology since 2004 with a research interest in applying advanced technology in orthopaedics. He was one of the pioneers in developing computer navigation application and 3D-printed patient-specific instruments in orthopaedic oncology surgery and has extensively published in the field. Currently, he is Clinical Associate Professor (Honorary) and the chief of Orthopaedic Oncology, Prince of Wales Hospital, the Chinese University of Hong Kong, Hong Kong.

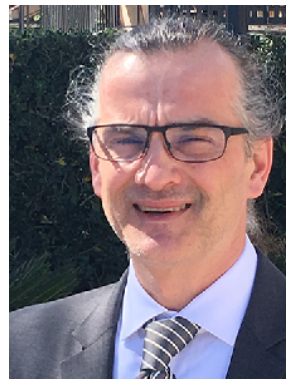

Peter Scheinemann is an engineer with more than 20 years' industrial experience in design and development of orthopaedic implants. Currently, he is the head of research and development in Implantcast GmbH company. He has been in charge of producing MUTARS tumour and revision prostheses, noninvasive growing prostheses in orthopaedics. Since 2013, he has introduced additive manufacturing for custom made implants and instruments and is one of the key opinion leaders in the field.

\title{
用于矫形外科的增材制造金属植入物
}

\author{
Kwok-Chuen Wong ${ }^{1 *}$, Peter Scheinemann ${ }^{2}$
}

摘要 金属植入物通常用于各种矫形外科手术，如骨折固定、脊柱内置物、关节置换和骨肿瘤手术等. 患者需要适应标准植入物的固定 尺寸, 这可能会导致对宿主骨的不匹配和其他临床副作用. 标准的传统植入物可能无法解决骨骼重建的挑战, 如种植体松动和骨肿瘤切除 后严重的骨骼畸形或骨质流失. 随着数字技术应用于医学成像, 如三维(3D)建模中的计算机编程和精确植入种植体的计算机辅助工具, 患 者特异性植入物在复杂的骨科重建中获得了更多关注. 与传统的减材制造相比, 增材制造技术是一种灵活的工艺, 它可以制备符合解剖学 标准的植入物以匹配患者解剖结构和手术要求, 还可以建立复杂的内部结构与多孔支架, 以促进骨整合和延长植入寿命. 尽管基础研究表 明增材制造 $(\mathrm{AM})$ 金属结构是良好的骨替代生物材料, 但关于此类新型植入物临床结果的同行评议文献还不是很多. 本文概述了通常用于 制造矫形外科植入物的金属材料, 描述了基于金属的增材制造技术和金属植入物的加工链, 介绍了AM植入物的特征及其在矫形手术中的 应用现状, 最后讨论了 AM植入物在矫形外科应用中存在的挑战. 